\title{
EXPERIMENTACIÓN DRAMATÚRGICA EN ROJAS ZORRILLA: ALTERNANCIA Y SIMULTANEIDAD ESPACIAL EN LOS TRABAJOS DE TOBÍAS
}

\author{
JAVIER RUBIERA FERNÁNDEZ \\ Université de Montréal
}

\section{RESUMEN}

El objetivo de este artículo es analizar la técnica empleada por Rojas Zorrilla, en una comedia religiosa de fuente bíblica, para representar de modo paralelo acciones dramáticas que se desarrollan simultáneamente en espacios dramáticos muy alejados. A pesar de basarse en procedimientos escénicos antiguos, al combinarlo con técnicas modernas el resultado es de tal originalidad que lo calificamos de «experimentación». Para valorar debidamente su modo de componer, se hace una estrecha comparación con el relato bíblico, con un auto del siglo XVI y con una comedia de Lope de Vega que tratan el mismo tema.

Palabras clave: Rojas Zorrilla; Tobías; dramaturgia barroca; simultaneidad espacial; Códice de Autos Viejos; Lope de Vega.

\section{ABSTRACT}

This article aims to analyse the technique used by Rojas Zorilla in a religious comedy of biblical derivation to represent, in a parallel way, dramatic actions that are simultaneously developed in very separate dramatic spaces. Although basing his approach on ancient stage procedures, by combining these with modern techniques the result is of such originality that we consider it to be «experimentation». In order to properly value his creative method, a close comparison is made between the biblical narrative, a sixteenth century auto, and a comedy by Lope de Vega that address the same subject.

Key words: Rojas Zorrilla; Tobit; Baroque dramaturgy; Simultaneous stages; Códice de Autos Viejos; Lope de Vega.

Desde el punto de vista de la configuración espacial, la obra de Rojas Zorrilla proporciona ejemplos modélicos que habrían podido ilustrar algunos de los procedimientos estudiados en mi monografía sobre la construcción del espacio en la Comedia (Rubiera, 2005). Estos ejemplos mostrarían el cuidado que el dramaturgo puso en tratar de solucionar los problemas que, en el momento de componer su poema dramático representable, iban saliendo al paso en relación con el modo de enlazar las acciones que suceden en lugares distintos. No habría más que recordar ciertas escenas de Lo que quiso ver el Marqués de Villena y de Abrir el ojo para ilustrar el pro- 
cedimiento del «espacio itinerante», es decir, un espacio dinámico de transición entre dos espacios dramáticos, moviéndose los actores de uno a otro siempre a la vista del espectador, sin ruptura de cuadro ${ }^{1}$. Por otro lado, precisamente en la comedia de magia sobre el Marqués de Villena se pone también en marcha un ingenioso recurso para representar simultáneamente escenas que ocurren en espacios dramáticos diferentes: durante la jornada segunda, el mago Fulgencio hace que el Marqués y Zambapalo vean lo que pasa en otros lugares a través de un espejo, y lo que ocurre en esos otros espacios se representa en el tablado central y en un segundo tablado ${ }^{2}$, entremezclándose los parlamentos de unas y otras acciones. Es un curioso ejemplo de escena compleja barroca con uso de múltiples espacios lúdicos que muestra un dominio seguro de la dramaturgia ${ }^{3}$ o técnica de composición de la pieza.

Quizás sea en Los trabajos de Tobías donde Rojas Zorrilla logre una mayor originalidad a la hora de solucionar problemas de simultaneidad y de movilidad espacial. Aunque ya Shergold se refirió a esta comedia en su monumental History $(1967,365-366)^{4}$ y a pesar de que R. MacCurdy (1968, 80-83) le dedicó párrafos esclarecedores, no creo que se haya valorado adecuadamente la significación y el mérito de Rojas al realizar este arriesgado experimento teatral. Las páginas que siguen tratan de llamar de nuevo la atención sobre esta comedia del poeta toledano, poniéndola en relación con las piezas de otros dramaturgos que trataron la misma materia bíblica. De este modo podremos profundizar en el conocimiento de la técnica de composición de Rojas.

Fenómeno común en su tiempo, la mayor parte de las veces el poeta del siglo de oro se sitúa ante un texto previo que le servirá de base para

${ }^{1}$ Los textos editados en la Segunda Parte de las comedias de don Francisco de Rojas Zorrilla (1645) conservan además en acotación las órdenes escénicas «Van andando por el tablado»; «anden por el tablado»; «van andando», indicaciones tan infrecuentes como concluyentes respecto a uno de los recursos más significativos de la movilidad espacial de la Comedia.

${ }^{2}$ La jornada segunda se desarrolla en un solo cuadro dentro de la cueva salmantina del mágico Fulgencio. Termina con un golpe de efecto extraordinario, aunque no fácil de visualizar. El mago ordena que todo desaparezca y la acotación indica: «Da un golpe con el baculo Fulgencio, y buelan a la par los dos tablados con todas las personas» $(1645 \mathrm{c}, 236 \mathrm{v})$. ¿Dónde se representaría la pieza y cómo se escenificaría esta acción? ¿para qué tipo de espacio teatral estaría pensada la comedia?

${ }^{3}$ Recientemente GARCÍA BARRIENTOS $(2006,442)$ ha propuesto como definición de dramaturgia: «la práctica del modo teatral de representar argumentos», que encaja muy bien en el contexto de este artículo.

${ }^{4}$ No comparto, sin embargo, su afirmación de que «this use of more than one stage may be compared with Calderon's Los tres mayores prodigios, and again suggests the courtyard of the palace» (366). Más allá de la apariencia superficial, el recurso a más de un tablado cumple funciones y responde a necesidades teatrales completamente diferentes en Rojas y en Calderón. 
componer un drama, tansformando los materiales narrativos de la fuente en acciones y en versos representables. Probablemente con el fin de responder a un encargo, en esta ocasión Rojas Zorrilla toma la pluma para componer un poema dramático sobre el relato bíblico de Tobías o Tobit. En el libro correspondiente del Antiguo Testamento se narran no solamente las historias de este personaje y de su hijo, también llamado Tobías, sino las peripecias de la desgraciada Sara, segunda acción que se acabará anudando con la principal en un final feliz. Según la versión de San Jerónimo, la Vulgata que debieron conocer Rojas y sus contemporáneos ${ }^{5}$, mientras los sucesos en torno a Tobías padre tienen lugar en Nínive, donde vive con su mujer y con su hijo, los de la vida de Sara transcurren en Ragés de Media, en casa de su padre Ragüel. El espacio intermedio entre Nínive y Ragés es el que el joven Tobías salva durante su viaje ${ }^{6}$, acompañado por el ángel Rafael (en forma humana y llamado Azarías) y por un fiel perrillo, con el fin de cobrar un antiguo préstamo de su padre a su primo Gabelo. Se encuentra con Sara, con la que se casa, vence al demonio Asmodeo (símbolo de la impureza y de la lujuria), cobra el préstamo y regresa a la morada de sus padres en Nínive, siempre guiado por el ángel y seguido por su perro. El procedimiento por el que Rojas actualiza de modo paralelo sobre escena dos acciones que suceden simultáneamente en dos lugares muy alejados, Nínive y Ragés, es de una gran originalidad y muestra la preocupación del dramaturgo por dar cohesión a su pieza, sin romper la representación en numerosos cuadros, y por solucionar mediante técnicas escenográficas y compositivas nuevas el problema de la alternancia de espacios dramáticos y el de la movilidad espacial. Hasta tal punto es así que creo que podemos hablar de «experimentación teatral».

Situado el poeta ante la narración bíblica, tiene que decidir qué elementos de la historia va a elegir para la adaptación teatral y, de entre ellos, cuáles serán mostrados sobre escena y cuáles se relatarán. En términos retóricos, Rojas se encuentra en la fase de creación que afecta principalmente a la inventio y a la dispositio. Sabe que los espectadores conocen la historia, que indudablemente tienen unas imágenes asociadas a esa narración sagrada y que sin duda esperan que una serie de acontecimientos obligatorios aparezcan ante sus ojos. Ya que estamos hablando de teatro, quieren presenciar y ver el sufrimiento y la paciencia de Tobías; su ceguera causada por el estiércol de unas golondrinas; el dolor de Sara por sus siete maridos muertos y por su situación desesperada; la oración y la fe de

5 Para el texto de la Vulgata, utilizo la edición de Priero (1963), con profusión de notas explicativas que dan buena cuenta del estado textual y de las soluciones de otras versiones, muy a tener en cuenta por lo que se explicará a continuación.

${ }^{6}$ Recuérdese que Gonzalo TORRENTE BALLESTER también dramatizó con gran libertad la leyenda bíblica en una pieza que tituló El viaje del joven Tobías, Bilbao, Ediciones Jerarquía, 1938. 
Tobías y de Sara ante un Dios que se decidirá finalmente a favorecerles con la ayuda angélica; los consejos de Tobías a su hijo antes de partir; el viaje del joven Tobías (acompañado por un ángel y por un perrito); el gran pez que trata de devorarle en el Tigris; la lucha entre el demonio y el ángel; la victoria de Tobías hijo sobre el demonio con ayuda del hígado del pez muerto; las bodas de Tobías y de Sara; el regreso a casa y la curación de la vista del padre con la hiel del pez. ¿Cómo ordenar estas acciones (a veces simultáneas), cómo dramatizarlas y espacializarlas dentro del molde de la comedia al uso? Por muy esperables que sean por el espectador, ¿tienen cabida en el drama todos esos episodios? ¿eliminará, entonces, algunas secuencias de la complicada trama para reforzar la unidad y la coherencia de la pieza? ¿será necesario introducir, paradójicamente, elementos nuevos, ajenos a la historia bíblica para captar la atención y el interés del público y para darles «gusto»? En este sentido, Rojas toma unas decisiones tan importantes como previsibles, pero sobre las que no podré desarrollar un comentario en el presente artículo: división de la comedia en tres jornadas; polimetría reducida al uso predominante del romance y de la redondilla ${ }^{7}$ (con un brevísimo lugar para la canción y la quintilla); introducción de la figura del gracioso, vehículo de acciones cómicas; adaptación al uso teatral moderno de la historia de amor de Tobías hijo y de Sara con la inclusión de un rival (Ioseph); amplificación de la trama política, al recrear en la primera jornada la relación entre el rey Senaquerib y su privanza, Tobías el Viejo.

Siempre con la mente puesta en el problema de la espacialización, a continuación me concentraré en analizar el modo en el que Rojas dramatiza las acciones ya presentes en la historia bíblica, comparándolo con la forma de proceder de otros dramaturgos que antes que él adaptaron la historia de Tobías: el anónimo que compuso hacia 1550 el Aucto de Tobías y Lope de Vega, quien hacia 1610 escribió una comedia sobre el mismo tema. Tal comparación nos servirá sobre todo para mostrar la diferencia dramatúrgica y de concepción estética entre Rojas y Lope en dos momentos distintos de la evolución de la Comedia, en este caso la religiosa de fuente bíblica. En este sentido compartimos un pensamiento de T. Kowzan, a propósito de la obra de Shakespeare, que nos servirá de guía en nuestro caso: «el resultado artístico y la originalidad del dramaturgo se revelan en el modo de tratar la fábula preexistente y de transformar el esquema temático inicial» (1992: 101).

${ }^{7}$ MacCurdy, en su introducción a la edición de Lucrecia y Tarquino, señaló que el 64 por ciento de los versos de las veinticuatro piezas editadas en las dos Partes de Rojas está escrito en romance y que las redondillas son el segundo tipo de estrofa más usado en la mayor parte de sus comedias (ROJAS ZORRILLA, 1963, 7). 
EL PROBLEMA DEL ESPACIO EN LA VERSIÓN BÍBLICA: NíNIVE, RAGÉS, ECBATANA.

Por si alguien recuerda con precisión el relato bíblico o siente la tentación de volver a leerlo ${ }^{8}$, conviene deshacer un posible equívoco en torno a la localización de las acciones según se puede ver en los textos modernos y en los antiguos, que difieren en su solución. Más o menos a comienzos del siglo V San Jerónimo hace la traducción del Libro de Tobías. Se vale de un intérprete que leyendo el texto en arameo (él lo llama caldeo) lo traduce al hebreo. San Jerónimo a su vez traduce del hebreo al latín. Es muy probable que tuviera a la vista una antigua versión latina, traducida del griego, de la que se separa en diversos pasajes. Una de las diferencias se refiere a los lugares donde se desarrolla la acción. En todas las versiones está claro que Tobías es un judío que vive en Asiria, concretamente en Nínive, y que su pariente Gabael o Gabelo habita en Ragés de Media ${ }^{9}$. Hacia allí es hacia donde viaja Tobías el joven, acompañado por Azarías y por su perro, para cobrar un préstamo. Pero ¿dónde vive Sara, la hija de Ragüel? ¿dónde se detienen los viajeros, antes de que Azarías continúe solo a Ragés? La traducción de San Jerónimo, la Vulgata, indica contradictoriamente que la casa de Sara está también en Ragés ${ }^{10}$, pero otras versiones, de las que provienen las ediciones modernas, señalan un tercer lugar, Ecbatana ${ }^{11}$. Efectivamente eso es lo lógico: Tobías el viejo envía a su hijo Tobías a casa de su pariente Gabelo en Ragés; por el camino Azarías le dice a Tobías que se detengan en Ecbatana, en casa de Ragüel y que allí se casará con Sara; mientras se celebran las bodas Tobías le pide a Azarías que vaya él solo a cobrar el préstamo a casa de Gabelo en Ragés; cuando regresa Azarías se van todos juntos de vuelta a Nínive, y se cierra así el viaje circular.

${ }^{8}$ Evidentemente han pasado los tiempos de MenÉndez Pelayo en los que todavía podía afirmar: «La comparación [entre los pasajes de la Biblia y la comedia de Lope] es fácil, y puede hacerla cualquiera abriendo su ejemplar de la Vulgata» $(1949,187)$.

${ }^{9}$ Esta ciudad correspondería a la actual Rey, situada unos 13 kilómetros al sureste de Teherán.

10 «Eadem itaque die contigit ut Sara, filia Raguelis, in Rages, civitate Medorum,...» (PRIERO, 1963, 79).

${ }^{11}$ Por ejemplo, la Nova Vulgata Bibliorum Sacrorum Editio (1979, 708), dice: «Eadem die contigit Sarae filiae Raguel, qui erat Ecbatanis Mediae...». En la Sagrada Biblia de la Biblioteca de Autores Cristianos se lee: «Aquel mismo día aconteció en Ecbatana de Media que Sara...» $(1981,575)$. En la versión de San Jerónimo «Ecbatana» sólo aparece una vez, pero como si fuera un monte donde estaría situada Ragés: «Rages, civitate Medorum, quae posita est in monte Ecbatanis» (pág. 95), que es lo que en el Aucto de Tobias se recogerá en boca del Angel como: «en Rrajes, çiudad nonbrada / que en el monte Agabata / esta puesta y situada» (vv. 227-230). La referencia a Ecbatana desaparece en Lope y en Rojas. Sobre Ecbatana se edificó la actual Hamadan, en Irán, y dista unos 300 kilómetros de Rey (Ragés). 
Sin embargo, la versión de San Jerónimo cae en una contradicción, pues si se ha dicho que Sara vive en Ragés, no tiene sentido que Tobías le pida a Azarías que haga un viaje a Ragés para encontrar a Gabelo. Es curioso notar que el poeta que compuso el Aucto de Tobías en el siglo XVI se dio cuenta del problema y en ningún momento dice que Sara viva en Ragés, como sí hace con Gabel ${ }^{12}$. Simplemente el ángel dirá a Tobías: «Do esta tu tio Rraguel / tenemos agora de yr» (vv. 341-342), sin que haya mayor especificación locativa. Lo que hará Rojas Zorrilla será simplificar las cosas y hacer coincidir en un mismo espacio (Ragés) a Sara, a su padre Ragüel y a Gabelo, y anular el viaje de Azarías a un tercer lugar, que se hace innecesario. Por su parte, Lope de Vega o bien no vio el problema o sencillamente no le importó, pues así se decía en el libro sagrado, y mantuvo la contradicción, siguiendo al pie de la letra el texto fuente.

\section{EL AUCTO DE TOBÍAS}

Esta pieza ${ }^{13}$ recogida con el número XXI en el Códice de Autos Viejos es según su editor, Léo Rouanet (1978, t. IV, 183), una de las mejores de la colección, desde el punto de vista literario. Hay noticia de una representación de una pieza con este título en Sevilla en 1561 y fue probablemente compuesta poco antes. Precedida de una breve introducción y rematada con un villancico, se trata de una composición de 530 versos, en quintillas, que simplifica mucho la fábula bíblica, eligiendo solamente algunos episodios para acomodarse a la brevedad de la representación típica del auto en esta época. Lo que importa señalar, aparte de la introducción de un bobo llamado Nabal que le da un ligero toque cómico en algún momento, es que el dramaturgo anónimo reparte la acción entre dos lugares que se van alternando bastante regularmente: casa de Tobías en Nínive / casa de Raguel y de su hija Sarra ${ }^{14}$, sin localizarla explícitamente, tal como hemos dicho. El anónimo autor divide la acción claramente en seis cuadros de extensión desigual:

1. Versos 21-265: interior de la casa de Tobías el Viejo / exterior de la casa / interior.

${ }^{12}$ Le dice el Padre al Hijo: «En la cibdad de Rrajes, / uno que llaman Gabel, / como tu fueses a el, / al momento cobraries / aquestos talentos del. / Querria, aunque heres muchacho, / que en Rajes a Gabel fueses, / y su escriptura le dieses, / porque luego sin enpacho / los talentos te trajeses» (vv. 176-180).

13 Para un análisis de este auto véase el ya clásico estudio de Mercedes de los REYES PEÑA (1988, t.1, 371-379; t. 3, 1078-1080) en el que, entre otras consideraciones, compara la pieza con los pasajes bíblicos correspondientes. Incluye igualmente un estudio comparativo del auto con la Consueta de la història de Tobies (núm. 34 del 'Ms. De Llabrés'), al que en seguida nos referiremos.

${ }^{14}$ Mantengo la grafía de los nombres según la edición de Rouanet. 
2. Versos 266-325: casa de Raguel y Sarra.

3. Versos 326- 415: Tobías hijo y el Angel Raphael de camino hacia casa de Raguel / casa de Raguel.

4. Versos 416-430: casa de Tobías el Viejo en Nínive.

5. Versos 431-480: casa de Raguel y comienzo del viaje de vuelta.

6. Versos 481-550: Regreso y reencuentro en Nínive.

La alternancia de lugares se encuentra ya de modo reiterado en el relato bíblico y si se quiere contar o representar esta historia, aun reducida a su expresión mínima, es imprescindible la doble localización y la referencia a los viajes intermedios. Tal como aparece editada la pieza en el Códi$c e$, para su representación se debió utilizar ya una técnica escénica consecutiva, es decir, no requiere un escenario múltiple simultáneo ${ }^{15}$. Las cinco veces en que se produce un cambio de localización, la acotación no deja lugar a dudas sobre el hecho de que los personajes de la escena anterior abandonan el tablado y posteriormente salen los de la escena siguiente ${ }^{16}$. Mercedes de los Reyes (1988, t.1, 378-379), al comparar el Aucto con la Consueta de la historia de Tobies señala una diferencia importante, muy significativa para la historia del teatro:

El empleo de la escena múltiple horizontal con la utilización de tres tablados (el de Tobías, Senequerib y Ragüel), el traslado de los personajes de unos a otros y el desarrollo de la acción tanto en estos como fuera de ellos hacen de la consueta una pieza de factura más medieval que la del Auct[o de] Tobias. Aunque en ésta se utilice también la escena múltiple [se refiere a la observación de Shoemaker sobre el primer cuadro], la falta de una continua presencia de todos los personajes ante el público por sus salidas de escena, los traslados de un lugar a otro realizados fuera del escenario mediante entradas y nuevas salidas, la ausencia de personajes manteniendo sus respectivos lugares cuando la acción se desarrolla en otro lugar... son clara muestra de una técnica escénica más avanzada en el auto.

Efectivamente, la técnica consecutiva empleada en el Aucto es ya la que se impondrá al desarrollarse el modelo de la comedia barroca y lógicamente es la que Lope de Vega utilizará en la Historia de Tobías. No obstante, como veremos, Rojas Zorrilla nos sorprenderá al volver a utilizar escena-

15 Aunque con alguna duda, SHOEMAKER (1957, 112 y 118) avanzaba la posibilidad de que, en el primer cuadro, se hubiera utilizado un montaje simultáneo con «dos 'lugares' para el interior y exterior de la casa de Tobías (206-210, 231-236)». Para la diferencia entre escenario múltiple simultáneo y espacio polivalente sucesivo o consecutivo, véanse, en mi estudio sobre la construcción del espacio en la Comedia (2005), los apartados «IV.2 El espacio dinámico en la comedia humanística y en el teatro del XVI» y «V.1 Posible origen de las subescenas simultáneas».

16 «Entranse, y salen Sarra y el Bobo», «Entrase, y sale[n] el Angel y Tobias», «Entranse, y sale la muger de Tobias», «Entranse, y sale[n] Raguel y Tobias y su muger y el Angel», «Entranse, y sale[n] Tobias y su muger». 
rios simultáneos: una vuelta al pasado que le permitirá, sin embargo, una original innovación.

\section{Historia de TOBÍAs DE LOPE DE VEGA}

Escrita probablemente hacia 1609 y publicada en la Parte $X V$ de 1621, está compuesta en 2935 versos dispuestos en una variada polimetría. Aunque predominen las redondillas, hay una importante presencia de quintillas y de romances, junto a décimas, sonetos, octavas, liras y versos sueltos, variedad que está bien en consonancia con la amplitud de temas y diversidad de tonos de la pieza. Por mezclar acciones humildes y plebeyas con otras reales y altas, partes graves con partes ridículas, Lope la llamará «tragicomedia» ${ }^{17}$. Este «sagrado exemplo de caridad y limpieza matrimonial» se ciñe muy ajustadamente al texto bíblico, tal como el propio Lope anuncia en su dedicatoria a Doña Marina Puente Hurtado de Mendoza y Zúñiga, donde afirma que ha tratado de hacer una traducción fiel del latín al castellano, aunque, con la licencia que permite la poesía, haya introducido «figuras dialogisticas de que tambien tenemos exemplo en los Cantares» (1621, 223r).

Desde un humilde perro hasta Dios mismo, todo cabe dentro del teatro de Lope. Nada le es ajeno. Melampo ${ }^{18}$ se llama el can y la voz divina incluso encuentra materialidad o concreción en «un marco con un velo de plata delante» (226v). Sobre escena todo es representable: Dios dándole una espada de fuego al Ángel, el pez que intenta devorar al joven Tobías, el ángel Rafael llevando por los aires al Demonio desde Media a Egipto..., por lo que el componente espectacular juega un papel importante. A pesar de que todas las acciones del libro sagrado se recogen, y se ven, a Lope le parece todavía poco: añade largas escenas inventadas para entreverar la historia seria con secuencias cómicas pastoriles y recurre al Libro de los Reyes (II, 17-20) para mostrar el intento fallido de conquista de Jerusalén por parte de Senaquerib. El resultado es desmesurado, un abigarrado conjunto barroco con 29 personajes nombrados en la lista de Figuras y no menos de 24 cuadros, es decir con un enorme número de entradas y salidas de personajes, una movilidad espacial continua (Nínive, Jerusalén, Cielo, orillas del Tigris, Ragés, Egipto) y un ritmo frenético que convierten a esta tragicomedia en un disperso, pero atractivo, mare magnum, ideal para

${ }^{17}$ Otras dos piezas de la Parte XV se identifican como tragicomedias: La Santa Liga y La hermosa Esther, esta última también basada en un libro del Antiguo Testamento.

${ }_{18}$ De las tres piezas sobre Tobías, en la de Lope es donde está más presente la figura del gracioso y fiel perrillo, que hasta aparece con nombre propio. Es uno de esos detalles del texto bíblico, que pasará a la iconografía de la historia, que Lope conserva con gran tino artístico. 
templar la cólera del público español ${ }^{19}$, según lo que Lope mismo recogió en el Arte nuevo, rigurosamente contemporáneo de la Historia de Tobías.

Esta es una de las muchas piezas en las que Lope decidió no seguir su propio precepto: «Quede muy pocas veces el teatro / sin persona que hable» (1998, 560-561). En más de veinte ocasiones queda el tablado vacío, porque, como hemos dicho, al seguir fielmente el libro sagrado la acción se mueve obligatoriamente entre Nínive y Ragés, alternancia de lugares que se ve además perturbada en la primera jornada por los episodios del cerco de Jerusalén, que obligan a entrarse a todos los personajes una vez que termina su acción y a dejar solo el teatro para permitir el cambio de espacio dramático. No hay otra opción en el escenario polivalente sucesivo del corral de comedias. La jornada segunda, que se cierra a orillas del Tigris, de camino entre Nínive y Ragés, consta de siete cuadros y es buena prueba de la alternancia mecánica a la que se ve forzado el dramaturgo, pues salvo una breve ruptura con una conversación celeste entre Dios y el ángel Rafael, se suceden los cuadros en una y otra localidad, centrándose en las historias de Tobías y de Sara respectivamente: Ragés / Nínive / Ragés / Nínive / Ragés.

El elevado número de segmentaciones dramáticas, la pluralidad de los lugares por los que se dispersaba la acción y la prolongación mecánica de la alternancia de espacios tuvieron que parecerle excesivos e inadecuados a Rojas Zorrilla cuando hacia 1640 se decidió a componer una nueva comedia sobre la historia de Tobías. El poeta toledano no puede ya seguir al maestro en esta concepción desmesurada de la escritura dramática y busca un nuevo camino. ¿Cómo conservar la fidelidad al relato bíblico y a la vez garantizar la cohesión de la pieza? ¿cómo mantener el interés del espectador con una acción rica y compleja sin caer en la dispersión episódica? ¿cómo lograr mayor unidad en la comedia sin por ello renunciar a plasmar la variedad que tanto deleitaba al público?

LOS TRABAJOS DE TOBÍAS DE ROJAS ZORRILLA: ALTERNANCIA, SIMULTANEIDAD Y FUSIÓN DE ESPACIOS

Publicada por Rojas en su Segunda parte de 1645, esta comedia probablemente haya sido representada en Toledo hacia $1640^{20}$. Es una larga pie-

${ }^{19}$ MenÉndez Pelayo valoró positivamente la comedia de Lope y condenó sin paliativos la de Rojas Zorrila, como luego veremos. De la de Lope precisó que la variedad de los acontecimientos estaba presentada con «estricta fidelidad escrituraria, no reñida ni un solo momento con el interés creciente de la acción y con la viveza del diálogo» (1949, 187).

20 «En una carta sin fecha, pero posiblemente de 1640, Pedro de Covaleda pide al Ayuntamiento [de Toledo] que encargue de hacer las apariencias de las comedias que ha de representar, entre ellas 'la comedia de Tobias', que podría ser Los trabajos de 
za de más de 3300 versos que Menéndez Pelayo condenó muy duramen$t^{21}$, pero no se trata ahora de hacer una lectura reinvindicativa para revalorizarla sino de insistir en lo que tiene de experimentación de técnicas dramáticas con el objeto de solucionar ciertos problemas de composición, como anunciábamos al principio del artículo.

Frente a la manera lopesca, el intento de contención de Rojas Zorrilla es bien evidente en esta comedia. Reduce el número de personajes a la mitad (catorce figuras aparecen en la lista de "personas que hablan en ella $\left.{ }^{22} \gg\right)$. Reduce el número de lugares a dos: Nínive y Rajés. Mientras Lope de Vega había segmentado su pieza en al menos veinticuatro cuadros, Rojas reduce el número de cuadros a siete: tres en la primera jornada, dos en la segunda y dos en la tercera. Desde el punto de vista métrico, casi usa únicamente redondillas y romances, lo que le confiere una unidad de tono bien diferente de la variada solución estilística del Fénix. Por último, no se obsesiona con la idea de tener que mostrarlo todo sobre escena y recurre con mayor frecuencia al relato de acontecimientos.

Es importante notar que la primera jornada transcurre íntegramente en Nínive, donde se dedica gran atención a la trama política, concentrándose en la paradójica relación entre el rey y el viejo Tobías, y al triángulo amoroso Tobías hijo-Sara-Ioseph, inventado por Rojas en un intento de dar mayor coherencia y profundidad a la relación entre los jóvenes, bastante desdibujada en el relato bíblico. Igualmente en esta jornada crea Rojas un personaje de gracioso (Morrión), vehículo de escenas cómicas en contrapunto con la figura de Tobías el viejo. Todas estas acciones nuevas se

Tobías de Rojas Zorrilla» (MARTínEZ Gil, GARCíA RuIPÉREZ y CROSAS, 2004, 107). El extraño o inusual espectáculo al que invita la lectura del texto dramático y esta breve noticia me llevan a pensar que la obra fuera representada no en el espacio de un corral de comedias sino en el marco de una fiesta religiosa al aire libre. En todo caso el objetivo de mi artículo no es especular sobre dónde fue representada y cómo se solucionarían concretamente, desde el punto de vista escenográfico, las indicaciones escénicas en acotación.

21 «Después de Lope, debemos mencionar a Rojas, que tuvo el mal gusto de echar a perder la delicada composición de su maestro, convirtiéndola en una monstruosa comedia, altisonante y gongorina, sin rastro de poesía ni de sentimiento místico, [...]. [...] es una de las que menos honran la memoria del bizarro autor de García del Castañar» (1949, 189).

${ }^{22}$ Debido a esta formulación, no aparece en la lista el perro de Tobías, que sin embargo está presente en varias escenas. No sé si el mismo perro u otro interviene también al comienzo de la segunda jornada, cuando sale a escena y le arrebata el pan que le han ofrecido como limosna al viejo Tobías, quien se lo permite, levantando la ira del resto de pobres: «Viejo loco, como aqui / tal injuria hazeis a Dios; / el pan que el Cielo os dà a vos / se lo dais a un perro?» (1645b, 142v). Esta escena en que todos comen el pan, a pesar de su ambientación muy poco solemnne, podría alegorizar la Eucaristía e inducir a pensar que la pieza se compuso para ser representada durante el Corpus Christi. 
anudan o se integran mucho mejor que las secuencias episódicas del asedio de Jerusalén y de los rústicos pastores cómicos de Lope. Frente a la desmesura y la dispersión de éste se aprecia un intento de concentración y de contención por parte de Rojas, quien se preocupa por lograr una mayor unidad artística.

Pero lo verdaderamente relevante, que hace que Los trabajos de Tobías sea una comedia especial, comienza en la segunda jornada en el momento en el que, ya en el cuadro segundo, la acción se localiza en Rajés. Hasta aquí todo transcurría como en cualquier comedia al uso representable en el escenario polivalente del corral, en el que los lugares se van presentando sucesivamente. Sin embargo, ahora que Tobías, allá en Nínive, acaba de ser cegado por las golondrinas y abandona la escena junto a su esposa, Morrión y un pobre, el teatro queda vacío unos instantes y la acotación correspondiente indica: En otro tablado que ha de estar en frente ${ }^{23}$ salen Sara, Raguel, y Iosef (1645b, 143v). En las primeras palabras de Iosef se indica inmediatamente que se ha producido un cambio de espacio dramático, que el dramaturgo ha decidido representar en otro tablado: "Yà hemos llegado los tres / a esta gran ciudad Rajes / ya del Rei libres estamos». Es tan importante el cambio que es la única vez en la comedia en que se va a utilizar un metro diferente del romance y de la redondilla, comenzando una corta serie de quintillas que contrasta claramente con el resto. A partir de aquí y hasta el final de la jornada comienzan a alternarse en los dos tablados a la vista del público las acciones que transcurren en Rajés y en Nínive, hasta que en cierto momento la alternancia se transforme en simultaneidad. De esta manera se da unidad al cuadro y se conserva la continuidad de la representación.

Los tres ejemplos de alternancia puede entenderlos el lector si nos fijamos simplemente en las acotaciones:

- Cuando termina la acción en Rajés, algunos personajes, estáticos, quedan sobre el tablado, mientras en el otro, que representa Nínive, comienza la acción: Raguel queda de rodillas, y Sara con un libro en la mano, y salen en otro tablado Tobías el viejo, y Ana guiandolo (144v).

- Siguiendo el mismo modelo, cuando acaba la acción de Nínive, Salen en el otro tablado Iosef, y Dina, que es donde estava Sara, y Raguel, y quedase Tobias echado en el suelo deste otro (144v).

- Después de que el demonio Asmodeo mate a Iosef, éste queda muerto en el suelo y se va el demonio, entonces salen En otro tablado el Arcangel Rafael, que se llamara Azarias, y Tobias el moço (145v).

${ }^{23}$ Como en el caso de Lo que quiso ver el Marqués de Villena, que recuerdo al comienzo del artículo, no hay que confundir este tipo de tablado con los tabladillos suplementarios laterales con los que se podía contar en el espacio escénico del corral de comedias. 
Se acerca entonces la comedia a su momento cumbre, y ahí es donde Rojas va a comenzar a utilizar la técnica de simultanear las dos acciones, entrelazando los diálogos de los personajes que están en Nínive con los que se producen en Rajés ${ }^{24}$, hasta que quede Tobías solo en su tablado y Sara sola en el suyo, los dos de rodillas, rezando fervorosa y resignadamente. A un lado un «santo varon», símbolo de la fe y de la paciencia en la adversidad; a otro lado una «justa mujer», símbolo de la castidad, de la pureza y de la obediencia. Entonces Baxan a cada tablado un Angel, cada uno con una pluma, y un libro en la mano (147r) para tomar buena nota de las oraciones y llevárselas a Dios. Tobías y Sara comparten versos y alternan redondillas completas hasta que cada uno de sus ángeles les comunica que sus oraciones están siendo escuchadas, tras lo que se van con un mensaje de paz.

Ya Raymond R. MacCurdy (1968, 83) vio bien el motivo por el que Rojas recurre a esta técnica:

Rojas' use of two stages was not motivated, as Cotarelo thought, by the need of resolve difficulties arising from the violation of the classical unity of place (which Spanish dramatists disregarded at every turn anyway). Rather, their use represents a deliberate effort to achieve unity greater than that of space by bringing into simultaneous view distant characters who are unified in their devotion to God.

Además Rojas Zorrilla ha logrado conservar prodigiosamente la simultaneidad de las oraciones de Tobías y de Sara, acertando atrevidamente a colocar al espectador en el mismo lugar de Dios. No se trata de un simple efecto espectacular para sorprender y agradar al auditorio. No cabe duda de que el poeta ha puesto su técnica dramatúrgica al servicio de la historia sagrada con el fin de situar al público en la perspectiva divina anunciada en el texto bíblico. Sólo desde ella es posible contemplar las dos escenas a la vez ${ }^{25}$ :

In illo tempore exauditae sunt preces amborum in conspectu gloriae summi Dei, et missus est angelus Domini sanctus Raphaël, ut curaret eos ambos, quorum uno tempore sunt orationes in cospectu Domini recitatae (Tobias 3, 24-25, en Priero, 1963, 85).

${ }^{24}$ Tras el encuentro entre Tobías hijo y sus padres, Sale al otro tablado Sara medio desnuda, y luego Dina, y Raguel, y habla cada uno en el suyo. Comienza aquí un ejemplo de «escena compleja barroca» (RUBIERA, 2005, 125-153) con subescenas simultáneas que transcurren en espacios geográficos separados por trescientos kilómetros.

${ }_{25}$ Para poder apreciar bien las diferentes soluciones técnicas, recordemos que en la segunda jornada de la Historia de Tobías Lope presenta una breve escena en la que la Voz de Dios explica a Rafael: «Dos oraciones oì / de dos personas, que aquí / me estan pidiendo favor. / En Ninive està Tobias, / y Sara vive en Rages, / favor quiero que les des» $(1621,235 r)$. 
Desde el punto de vista religioso, esta es la escena principal de la comedia, donde se muestra el poder de la oración ejemplificado en un santo varón y en una justa mujer sometidos a la obediencia de Dios y entregados a su voluntad. Rojas Zorrilla podía renunciar a mostrar la escena en el Tigris cuando el gran pez intenta devorar al joven Tobías, pero no esta otra, nuclear, que convierte en el momento más emotivo de la obra. Para ello recurre al modo antiguo de escenificación múltiple simultánea, combinándolo con la complejidad que la comedia moderna había logrado al posibilitar el entrecruzamiento de diálogos en dos espacios diferentes.

Al final de la comedia aún le aguarda al espectador una sorpresa escenográfica que en este caso tampoco será gratuita, pues cumple una función dramática importante: por un lado fundir en uno los espacios de Rajés y Nínive, con el valor simbólico añadido que tiene tal acción; por otro lado, solucionar con brevedad el viaje de vuelta de los recién casados, Sara y Tobías mozo, sin tener que romper el cuadro y sin alargar más una comedia ya muy extensa. Ante el deseo del joven Tobías de regresar y de llegar pronto a casa de sus padres, Azarías, el ángel, se presta a hacerlo de inmediato: «Yo (que a tu piedad asisto) / à Ninive os llevarè / en un instante». Tobías duda de que sea posible («mas si ai / veinte dias de camino, / no podrà ser») y Azarías insiste: «Fia de mi / y venid todos conmigo». La acotación indica: Lleva el tablado donde estàn al otro, con todos los que ai en èl, tras lo que el ángel dice: «Esta es Ninive, y esta / tu misma casa» (153r), con lo que se han salvado los trescientos kilómetros de distancia en un instante ${ }^{26}$.

De este modo creo haber ilustrado cómo Rojas Zorrilla experimenta nuevas vías dramáticas expresivas en relación con el modo de enlazar las acciones que suceden en lugares distintos, lo que confiere a Los trabajos de Tobias una gran originalidad al solucionar problemas de movilidad y de simultaneidad espacial. Esto hace que, desde el punto de vista dramatúrgico, es decir, de la técnica de construcción de la pieza, tenga una relevancia especial en la historia de nuestro teatro clásico.

\section{BIBLIOGRAFÍA}

Charland, Pierre, Le jeune Tobias et son ange. Filiation, autonomie et identité, Paris, Médiaspaul, 2006.

CotARelo y Mori, Emilio, Don Francisco de Rojas Zorrilla, noticias biográficas y bibliográficas, Madrid, Imprenta de la Revista de Archivos, 1911.

26 «The two stages are used again in the third act, and at the end one of them flies away with all the characters on it, as in the Villena play» (SHERGOLD, 1967, 366). En mi opinión no se desprende obligatoriamente de la acotación el que el tablado tenga que volar por los aires, como sí es el caso de Lo que quiso ver el Marqués de Villena. 
Drewermann, Eugen, Dieu guérisseur. La légende de Tobit ou le périlleux chemin de la rédemption. Interprétation psychanalytique d'un livre de la Bible, Paris, Éditions du Cerf, 1993.

FitzMayer, Joseph A., Tobit, Berlin-New York, Walter de Gruyter, 2003.

GARcía BARRIENTOS, José Luis, «La Teoría literaria en el fin de siglo: panorama desde España», Revista de Literatura, LXVIII, N. ${ }^{\circ}$ 136, julio-diciembre 2006, 405-445.

GonZÁLEZ CAÑAL, Rafael, «Francisco de Rojas Zorrilla», Historia del teatro español, coordinada por Javier Huerta Calvo, Madrid, Gredos, t. 1, 1159-1189.

KowZAN, Tadeusz, Literatura y espectáculo, Madrid, Taurus, 1992.

MacCurdy, Raymond R., Francisco de Rojas Zorrilla, New York, Twayne Publishers, 1968.

MARTínez GiL, Fernando, Mariano García Ruipérez y Francisco Crosas, «Calderón de la Barca y el Corpus toledano de 1640: recuperación de una carta autógrafa en el Archivo Municipal de Toledo», Criticón, 91, 2004, pp. 93-120.

Menéndez Pelayo, Marcelino, Estudios sobre el teatro de Lope de Vega I, edición preparada por Enrique Sánchez Reyes, Santander, CSIC, 1949, pp. 186-190.

Nova Vulgata Bibliorum Sacrorum Editio, Sacros-oecum. Concilii Vaticani II ratione habita iussu Pauli PP. VI Recognita Auctoritate Iioannis Pauli PP.II Promulgata, Libreria Editrice Vaticana, 1979.

PEDRAZA JimÉnEZ, Felipe B., «Rojas Zorrilla: un teatro para los oídos», Escenografía y escenificación en el teatro español del siglo de oro, Roberto Castilla Pérez y Miguel González Dengra (eds.), Granada, Universidad de Granada, 2005, pp. 403-421.

Priero, Giuseppe, Tobia, Roma-Torino, Marietti, 1963.

Reyes PeÑA, Mercedes de los, El 'Códice de Autos Viejos'. Un estudio de historia literaria, (3 tomos), Sevilla, Alfar, 1988.

Rojas Zorrilla, Francisco de, «Abrir el ojo», Segunda parte de las comedias de don Francisco de Rojas, Madrid, Francisco Martínez, 1645a, pp. 112v-131.

—, «Los trabajos de Tobías», Segunda parte de las comedias de don Francisco de Rojas, Madrid, Francisco Martínez, 1645b, pp. 131v-153.

—, «Lo que quería ver el Marqués de Villena», Segunda parte de las comedias de don Francisco de Rojas, Madrid, Francisco Martínez, 1645c, pp. 219r-245.

—, Lucrecia y Tarquino, edición de Raymond R. MacCurdy, Alburquerque/New Mexico, Universidad de New Mexico Press, 1963.

-, Entre bobos anda el juego, edición y estudio preliminar de Maria Grazia Profeti, Barcelona, Crítica, 1998.

-, Donde no hay agravios no hay celos. Abrir el ojo, Felipe B. Pedraza Jiménez y Milagros Rodríguez Cáceres (eds.), Madrid, Castalia, 2005.

RouAnet, Léo (ed.). «Aucto de Tobias», Colección de autos, farsas y coloquios del siglo XVI, Hildesheim-New York, Georg Olms Verlag, 1979, Band I, pp. 358-376; Band IV, pp. 183-185.

RUBIERA FERNÁNDEZ, Javier, La construcción del espacio en la comedia española del siglo de oro, Madrid, Arco/Libros, 2005.

Sagrada Biblia, versión directa de las lenguas originales por Eloíno Nácar Fuster y Alberto Colunga Cueto, Madrid, Biblioteca de Autores Crisitianos, 1981.

Shergold, N. D., A Histoy of Spanish Stage from Medieval Times until the End of the Seventeenth Century, Oxford, Clarendon Press, 1967.

ShOEMAKer, W. T., Los escenarios múltiples en el teatro español de los siglos XV y $X V I$, Cuadernos del Instituto del Teatro, 2, Barcelona, Diputación Provincial de Barcelona, 1957.

Trambaioli, Marcella, «Una obra mitológica de corral: Progne y Filomena de Rojas Zorrilla», Felipe B. Pedraza Jiménez y Rafael González Cañal (eds.), La década de 
oro de la comedia española: 1630-1640, Actas de las XIX Jornadas de teatro clásico. Almagro, julio de 1996, Universidad de Castilla-La Mancha/Festival de Almagro, Almagro, 1997, pp. 263-280.

Vega, Lope de, «Historia de Tobías», Décima quinta parte de la comedias Lope de Vega Carpio, Madrid, viuda de Alonso Martín, 1621, pp. 222v-246.

- , «Arte nuevo de hacer comedias en este tiempo», Rimas humanas y otros versos, edición de Antonio Carreño, Barcelona, Crítica, 1998, pp. 545-568.

Zimmermann, Frank, The Book of Tobit. An English Translation with Introduction and Commentary, New York, Harper \& Brothers, 1958. 